\title{
Establishment of Avicennia marina mangroves on accreting coastline at Sungai Haji Dorani, Selangor, Malaysia
}

\author{
Noraini Mohd. Tamin, Rozainah Zakaria, Roslan Hashim, Yu Yin
}

Mangroves are complex ecosystems that provide coastal bioshield to save guard coastal habitats and societies from natural disasters. Following the Indian Ocean tsunami of 26 December 2004 it was reported that mangroves and coastal forests are effective in mitigating tsunami waves through hydraulic resistance (drag and impact force) owing to bottom roughness and vegetation (Hamzah and Sofwan, 2007). Mangrove ecosystems have been reevaluated and its coastal protection value actually exceeds its direct-use values (such as forest harvesting and mari-culture) by over 97\% (Sanford, 2009). Thus mangroves are very valuable for protection against strong wave surges and tsunamis. There is a need to conserve and restore mangroves at the national and global levels.

Mangrove ecosystems, especially along exposed and waveimpacted coastlines, once degraded may require innovative and relatively expensive bio-technical methods for restoration, compared to the restoration of abandoned ponds that may only need the dykes to be broken down to enable natural seeding of the area. Indeed such innovative efforts require technical inputs from several specialists (for example engineers, hydrologists, ecologists and botanists) to plan bio-technical options for initial ground stabilisation and subsequent mangrove replanting works. It usually requires the construction of a hard and flexible breakwater that facilitates seawater flushing of the restoration area at high tide, and geostructures to trap sediments when the tide subsides. Inputs from ecologists are also vital in planning innovative pre-planting trials, species selection and enrichment planting, that are crucial for the success of the restoration efforts.

Along specific coastline of the State of Selangor, coastal erosion has threatened the stability of a stretch of earth bund (or dyke) that protects inland villages and economies. Fringe mangrove forests are slowly being washed away at critical areas, for example at the restoration area, which does not have any forest left. There is a need to construct a breakwater to protect the coastline as an immediate mitigating measure against coastal erosion and to plant mangroves 
behind it as a long-term green protective barrier.

A similar strategy was adopted earlier in the rehabilitation of mangroves along the upper Gulf of Thailand (Winterwerp et al., 2005) using rubble mound and detached breakwater parallel to the coast as erosion control measures. A recent study on erosion and accretion processes at the Chao Praya River delta in Thailand has produced encouraging results (Uehara et al., 2010). It was reported that seasonal variation in seabed elevation (approximately $30 \mathrm{~cm}$ ) was caused by seasonal changes in wave direction and height. A breakwater that was constructed contributed to a net rise in seabed level at sites behind the structure.

At Sg, Hj. Dorani the cost of constructing hard breakwater is substantial, at about USD 142,000 ha_1. Initial investigations on coastal rehabilitation and mangrove restoration using integrated bio-technical approaches, have produced encouraging results especially significant accretion and stabilisation of the restoration area after construction of the concrete (L-Block) breakwater (Hashim et al., 2010). This paper is an update on mangrove planting efforts and resource recovery at $\mathrm{Sg}, \mathrm{Hj}$. Dorani, Malaysia. The use $1 \mathrm{e} 1.3 \mathrm{~m}$ tall Avicennia marina wild saplings as test plants for eventual enrichment planting works (described in this paper) is an innovative strategy to speed up the greening process.

There was an attempt to discredit Government-funded and multidisciplinary coastal protection and mangrove rehabilitation research activities at Sungai Haji Dorani as seen in a misleading review by Stanley and Lewis (2009). This paper does not reflect actual research methods and long-term findings of legitimate researchers from the Forestry Research Institute of Malaysia (FRIM) and the University of Malaya (our research team). In addition the paper contains incorrect information (for example an incorrect date (1932e1942) was cited as the date when the earth bund or dyke was constructed (the bund was actually constructed between 1990 and 1992) and plagiarised data (for example the non-citation of the source of Fig. 7a related to accretion at the restoration area). The correct interpretation of technical data on hard engineering works and accretion within the project area, has been well documented by members of our research team (Hashim et al., 2010; Kamali et al., 2010). Indeed, Stanley and Lewis have prematurely (based on the first author's field observations during the first year of a three-year project) and wrongly predicted that our mangrove rehabilitation works would fail. On the contrary in November 2010, Avicennia marina recruits have borne flowers and fruits, a definite indication of biological success (Primavera and Esteban, 2008). Furthermore A. marina saplings (that were planted in July 2010) are showing good survival rates and height increments as discussed in this paper 
Before the Asian tsunami of 26 December 2004, Avicennia

marina was not the choice species for commercial planting.

Furthermore, this species is a prolific pioneer along the far shore sheltered coastlines and estuaries. Instead Rhizophora apiculata was the favourite choice (due to its commercial value as poles and logs for charcoal) andwas often planted even at unsuitable far shore and exposed areas. Avicennia sp. has limited commercial value, as firewood but is suitable as protective green shelterbelts and coastal bio-shields against wave surges and tsunamis. In the Philippines, Rhizophora sp. was also the preferred choice for mangrove restoration (Primavera and Esteban, 2008) and this is probably an outcome of weak ecological background of many forestry staff and the influence of American ecology (where Rhizophora mangle dominates neotropical mangroves) in Philippine Forestry practices. Currently Avicennia sp. has been widely planted in degraded mangrove sites throughout the Philippines.

Description of the study area

Project site

The study area is located at Sg. Hj. Dorani, about $90 \mathrm{~km}$ to the north of Kuala Lumpur, on the west coast of Peninsular Malaysia. The site location map is shown in Fig. 1. The environmental conditions, description of the existing mangrove stands and technical details regarding the construction of a hard breakwater (Lblock revetment) and accretion have been published (Hashim et al., 2010).

Hard breakwater construction for mangrove restoration near Sg. Hj, Dorani

For this study a breakwater has to be constructed to reduce the intensity of the waves that hit the shoreline and to facilitate accretion within the restoration area to a height that is suitable for establishment of Avicennia marina saplings. A segmented, concrete breakwater known as the L-Block revetment was constructed in June 2008 and all technical details have been well documented (Hashim et al., 2010).

\section{Full text available at :}

http://ac.els-cdn.com/S0272771411002496/1-s2.0-S0272771411002496- main.pdf? tid=838bdfae-66e4-11e38ffc-00000aab0f02\&acdnat $=1387261919766 \mathrm{b71e4d405cb2061455f5381623226}$

http://www.sciencedirect.com/science/article/pii/S0272771411002496 